\title{
Scientific evidence of sustainable plant disease protection strategies for oats in Sweden: a systematic map
}

\author{
Elisa Vilvert ${ }^{1}$, Åke Olson ${ }^{1}$, Ann-Charlotte Wallenhammar ${ }^{2}$, Jonas Törngren ${ }^{1}$ and Anna Berlin ${ }^{1 *}$ (i)
}

\begin{abstract}
Background: Oat (Avena sativa L.) is an important cereal crop for livestock feed and human consumption. The largest oat-producing countries are located in the Northern Hemisphere with Sweden as the tenth largest producer. Oat production is challenged by different diseases that can lead to significant yield reductions and impaired grain quality. The use of efficient and sustainable plant protection management is of great economic and ecological importance. The systematic map in this study aims to provide a knowledge base inventory and to identify areas that need to be researched in the future in terms of plant disease management for more sustainable oat production.
\end{abstract}

Methods: Literature searches were conducted in both academic bibliographic databases and relevant online sources of grey literature. A time-span restriction of 40 years (1978-2018) was applied to the searches. English was used in all searches, and Swedish, Norwegian and Danish languages were used in the grey literature searches. The screening process, which followed a protocol with eligibility criteria, was conducted at three levels: title, abstract and full text. Metadata incorporating bibliographic information, study location, climatic zone, disease name, the common and scientific names of the disease-causing organism, pathogen type, intervention and management methods, diseased plant part, plant stage, and outcome were extracted from the studies and included in the systematic map. The systematic map findings are visualized in figures and tables and described. All included studies can be found in a searchable database.

Review findings: A total of 58 eligible articles, most $(n=51)$ from scientific journals published in English, were included in the systematic map. A majority of the studies were conducted in the Northern Hemisphere in temperate climatic zones, where most of the world's oats are produced. The earliest article was published in 1980, followed by an oscillating temporal distribution of articles over the following years. By country, Canada had the highest number of articles, and by region, Europe had the highest number. Fungi were the most studied pathogen type, and a total of 16 different diseases were reported. Fusarium head blight (Fusarium spp.) and crown rust (Puccinia coronata) were the most studied diseases. In total, 17 different intervention management approaches for controlling the diseases were analyzed in the articles, with cultivar resistance and pesticide application as the most studied methods.

Conclusion: The map highlights the low quantity of available relevant field research on oat disease management. To our knowledge, this is the first systematic map of crop protection. This map provides a database of scientific literature that can be used to develop sustainable disease management strategies. The method used in this study has great potential and can also be used to benefit other crops. Research is often based on the availability of funding, and this

*Correspondence: anna.berlin@slu.se

1 Department of Forest Mycology and Plant Pathology, Swedish

University of Agricultural Sciences, Box 7026, 75007 Uppsala, Sweden

Full list of author information is available at the end of the article permits use, sharing, adaptation, distribution and reproduction in any medium or format, as long as you give appropriate credit to the original author(s) and the source, provide a link to the Creative Commons licence, and indicate if changes were made. The images or other third party material in this article are included in the article's Creative Commons licence, unless indicated otherwise in a credit line to the material. If material is not included in the article's Creative Commons licence and your intended use is not permitted by statutory regulation or exceeds the permitted use, you will need to obtain permission directly from the copyright holder. To view a copy of this licence, visit http://creativecommons.org/licenses/by/4.0/. The Creative Commons Public Domain Dedication waiver (http://creativeco mmons.org/publicdomain/zero/1.0/) applies to the data made available in this article, unless otherwise stated in a credit line to the data. 
map could be a useful tool for researchers and funding organizations to identify relevant research topics that need to be further studied. In addition, this systematic map offers a useful tool for field-based advisors in providing scientifically relevant crop protection strategies for farmers.

Keywords: Avena sativa, Oats, Disease control, Crop management, Pathogen

\section{Background}

Oat (Avena sativa L.) is the sixth most cultivated cereal crop worldwide and is used for both livestock feed and human consumption $[1,2]$. It is believed that oat domestication started between 4500 and $400 \mathrm{BC}$ in Europe when this region faced a cool and wet climate period unfavorable for already domesticated wheat and barley genotypes [2,3]. The historical importance of oat is mainly related to its traditional use as on-farm animal feed, especially for workhorses [3]. Furthermore, oat was an important grain crop for human consumption in some European countries with special importance during the Irish famine period (1740-1741), where it was used in soups to mitigate starvation $[2,3]$.

Worldwide oat grain production faced a progressive decrease between 1971 and 1998, from 46.9 to 26.3 million metric tons [4]. Since then, global production has stabilized and now averages approximately 24 million metric tons [4]. The use of oat for livestock feed accounts for $70 \%$ of total oat grain production [5]. This global production decline was due to a combination of different factors, including (i) the increase in farm mechanization that required fewer workhorses resulted in lowered demand for oat feed; (ii) the lack of new oat-based products being developed; and (iii) the dominance of more profitable crops such as wheat, barley and maize $[1,5,6]$. However, this decrease has recovered somewhat due to the increased demand for oat products for industrial use (cosmetics, pharmaceuticals, etc.) and for human consumption based on the increased understanding of its nutritional benefits (e.g., $\beta$-glucan and fiber content) and the promotion of oat as a health food $[7,8]$. The development of new oat-based products is expected to further promote an increase in oat production, especially in North America and Europe [7].

Oat production is favored by moderate temperatures and high levels of rainfall, and thus, this crop is sensitive to heat and drought $[1,5]$. Given its sensitivities, the largest amounts of oat production occur in temperate regions in Europe and North America [1, 4]. In 2019,

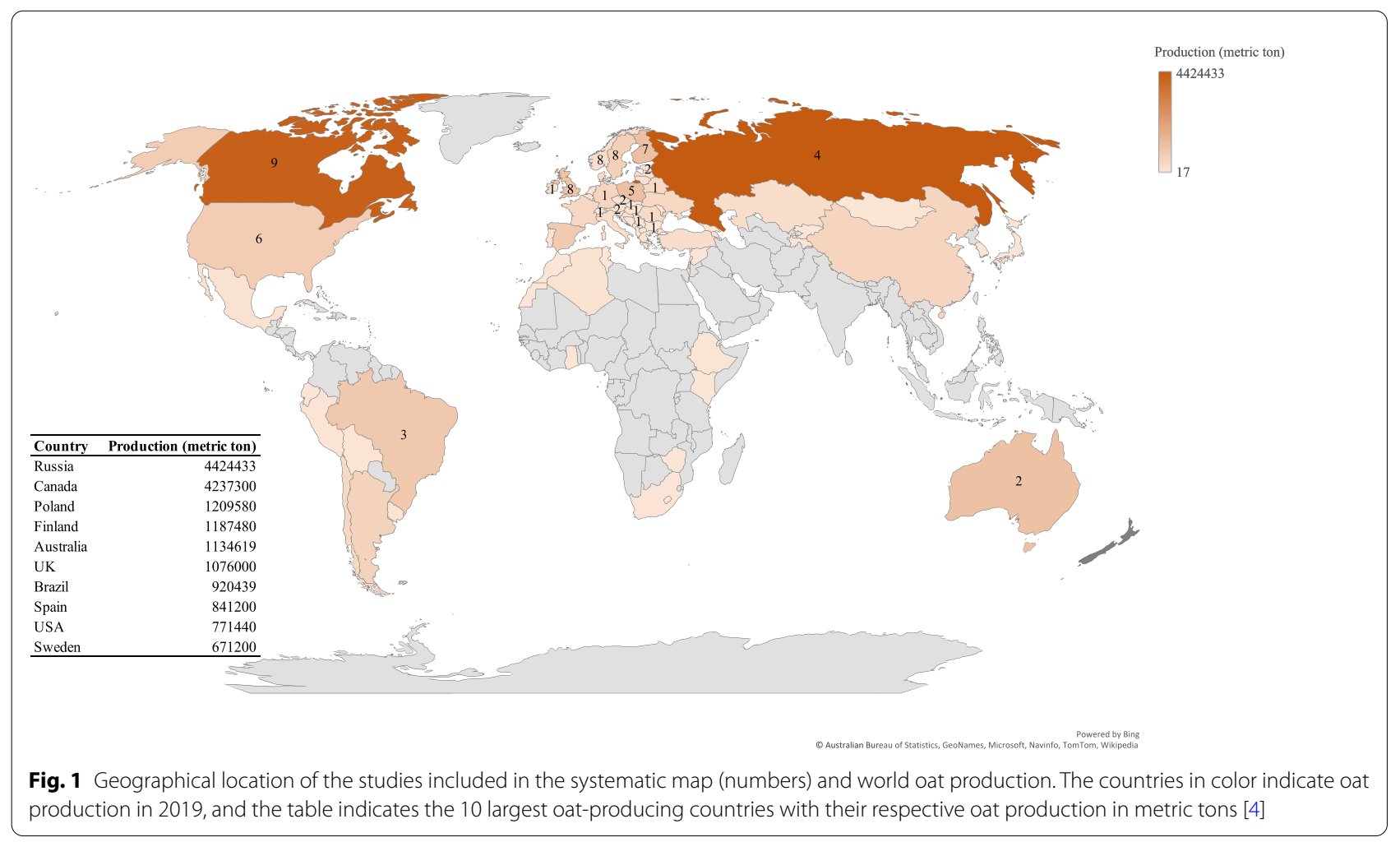


Russia was the world's leading oat producer with a total production of 4.42 million metric tons, closely followed by Canada with 4.24 million metric tons (Fig. 1). Oat is also an important crop in Nordic countries, and in 2019, Finland and Sweden were the fourth and tenth largest oat producers in the world and the second and third largest exporters, respectively [4]. Oat is also produced in relatively small quantities in cold regions in the Southern Hemisphere in countries such as Australia, New Zealand and Brazil (Fig. 1). In the Northern Hemisphere, both spring and winter cultivars are grown, and in the Southern Hemisphere, mainly spring cultivars are grown during the winter season [1]. Overall, most of the world's oat production comes from spring cultivars due to the lack of winter hardiness in oats [6].

Oat is widely grown in crop rotations and as a winter cover crop, especially in the USA and South America, as sustainable agriculture practices for soil conservation [1]. As a cover crop, oat can be integrated into no-tillage systems by providing surface residues to improve soil quality and conservation. Furthermore, oat is grown as a forage crop in regions with climatic conditions unfavorable for oat grain production, such as cold areas and regions with short growing seasons, or at high latitudes or high altitudes in warmer subtropical and Mediterranean climates [7]. Oat forage production is important in South America, the Indian subcontinent, New Zealand, Australia, and the USA [3]. Oat can be used as forage in different ways, such as green feed for grazing purposes, dual-purpose forage (graze and grain production), hay, silage, and straw [1].

Plant diseases can lead to a significant reduction in oat yield and impaired grain quality, and these diseases are caused by a range of different microorganisms, including fungi, bacteria, viruses and nematodes. Host resistance, the use of healthy seeds and fungicides are currently the most applied disease management strategies to control the main oat diseases [3, 9]. Fungicides are widely applied by farmers to control fungal diseases despite the economic costs of these methods to farmers and the risk of negative environmental consequences. Host resistance can be more effective than fungicides, although currently, there is no effective resistance available toward the most important diseases [10, 11]. Another problem is the evolution of fungicide resistance in plant pathogens due to the continual and indiscriminate use of these chemicals. In the European Union (EU), new legislation is being implemented to limit the negative environmental impacts of pesticides, and as a result, several active substances have been or will be prohibited for agricultural use [12]. In addition, the EU directive on sustainable use of pesticides (2009/128/EC) underlines the importance of production of a healthy crop with the least impact on the agroecosystem. This directive legislate the implementation of integrated pest management (IPM) and encourages the use of nonchemical measures. As a result, the development and application of alternative control strategies for sustainable agriculture are required [12].

\section{Stakeholder engagement}

Oat is the third most important crop in Sweden, and this map was developed to be applicable to Swedish conditions. The overall aim of this map was to provide evidence base for plant disease protection strategies available for oat production in Sweden. The development of this systematic map and the formulation of the primary question were actively discussed with stakeholders, other researchers, and a representative from the Plant Protection Centers at the Swedish Board of Agriculture. To ensure the relevance of the primary question, the group was also consulted about the development of the eligibility criteria.

\section{Objective of the review}

This systematic map describes the volume and main characteristics of field-based plant protection research based on a systematic search of scientific literature databases and grey literature searches. The objectives were to develop an inventory of the knowledge base, provide an overview of the plant disease protection measures used for oat with scientific support, identify knowledge gaps and research areas and provide a knowledge base for plant protection specialists as well as policy-makers when allocating research resources. The map builds on a protocol previously published by Berlin et al. [12]. This systematic map focuses on studies based on the production of oats from the climatic zones relevant for Swedish crop production. According to the Köppen-Geiger climate classification [13], Sweden has three different climatic zones: Dfc, Dfb and Cfb. The first two zones are classified as snow (D) and fully humid (f) climates, and they differ by a cool summer (c) and a warm summer (b). The last climate is a warm temperate $(C)$ and fully humid climate (f) with a warm summer. The climate zone Cfa representing a warm temperate $(\mathrm{C})$ and fully humid climate (f) with a hot summer (a) was also included because with climate change, this type of climate is expected to occur in southern Sweden in the future [13].

The primary question of this systematic map was the following: What is the evidence base of plant disease protection measures and strategies available for oat production in Sweden?

Components of the primary question:

Population: Oat (Avena sativa) crops in climatic zones (Dfc, Dfb, Cfb and Cfa) relevant to Swedish oat production. 
Intervention: Any measure to control crop diseases in agricultural fields, including both direct and indirect interventions.

Comparator: No intervention (control) and/or when different interventions were compared.

Outcome: Yield or outcome measured as yield per unit area, disease suppression, and/or increase in crop quality.

\section{Methods}

The map in this study builds on the protocol previously published by Berlin et al. [12]. The method follows the Collaboration for Environmental Evidence Guidelines and Standards for Evidence Synthesis in Environmental Management [14] and conforms to the ROSES reporting standard [15] (see Additional file 1).

\section{Deviations from the protocol}

The methods used to develop this map deviate from the protocol [12] in a few aspects:

- The protocol was designed for six crops; however, this map catalogs information only about one of the selected crops, oat. The other crops listed in the protocol will be considered for publication in separate systematic maps.

- To facilitate the Google Scholar search, the software Publish or Perish [16] was used.

- Articles in Norwegian and Danish were included as relevant languages due to their relevance to the Nordic region.

- The search terms for the grey literature were not specified in the protocol, and the process for conducting the search is described in the methodology below.

- The list of studies removed at the title, abstract and full text levels are provided as an Excel file as opposed to being included in the EndNote library file in the additional material.

- The intervention and management data codings were merged for analysis of the results since several studies used different kinds of agricultural practices (described as management) as intervention methods for disease control.
- The publications included in the category "Book, reviews and reports" were categorized into subcategories as described below.

\section{Search for articles}

An extensive search for literature was conducted in academic bibliographic databases and relevant online sources of grey literature. The search was conducted in English and included the scientific name of the crop. The search string developed for the scientific databases was structured in four thematic blocks: crop, disease-causing organism, plant disease terms and outcome. The blocks were combined using "AND", and the final search string used is in Table 1.

A shorter search string was created for AGRIS and Google Scholar to adapt to the limits of these databases: (fung* OR oomycete* OR nematod* OR bacter* OR virus" OR viral OR viroid* OR pathogen") AND (Oat OR "Avena sativa").

A time-span restriction that included literature published over 40 years (1978-2018) was applied. For all searches, the following data from the search process were recorded: date of search, database and platform name, institutional subscription used to access the database, search string, and number of hits (Additional file 2). The following academic bibliographic databases were used to search for studies:

1. Web of Science Core Collection (http://webofknowl edge.com/WOS).

2. Biosis Citation Index (http://webofknowledge.com/ $\mathrm{BCI})$.

3. CABI: CAB Abstracts and Global Health (http:// webofknowledge.com/CABI).

4. Scopus (https://www.scopus.com/).

5. AGRIS (http://agris.fao.org/).

Databases 1-3 were accessed through the Swedish University of Agricultural Sciences (SLU) subscription at Web of Sciences (v.5.30). Databases 4 and 5 were accessed directly through their websites.

Table 1 Search string with four thematic blocks combined using the operator "AND"

\begin{tabular}{ll}
\hline Thematic block & Search string \\
\hline Crop & Oat OR "Avena sativa" \\
$\begin{array}{l}\text { Disease-causing organisms } \\
\text { Plant disease terms }\end{array}$ & $\begin{array}{l}\text { "Dung* OR oomycete* OR nematod* OR bacter* OR virus* OR viral OR viroid* OR pathogen* } \\
\text { "risk management" OR "biological control" OR"disease control" OR IPM OR "integrated pest } \\
\text { management" OR "plant defen*" OR resistance OR "disease develop" }\end{array}$ \\
Outcome & "Plant health"OR yield* OR qualit* OR harvest OR produc* OR "pathogen reduction" \\
\hline
\end{tabular}


The grey literature search covered three different types of sources. First, three databases for preprint archives were used to identify prepublished research studies: bioRxiv (http://www.biorxiv.org), PeerJ (http://www. peerj.org), and arXiv (http://www.arxiv.org). Second, a search in Google Scholar using Publish or Perish software [16] was performed to extract the first 1000 search results, and third, searches were performed on the webpages of 21 relevant organizations listed in Additional file 2 . These organizations were selected to cover national and international research organizations and governmental bodies active within the relevant climatic zones.

For the searches of the webpages of different organizations, a more limited search was conducted using only the crop name in English and the crop scientific name in Latin: "Oat" and "Avena sativa". For the Swedish, Norwegian and Danish webpages, searches were also carried out using the crop name in their respective languages, and for the Finnish webpages, the searches were carried out using the Swedish and English versions of the webpages.

The results from the searches were imported to an EndNote X9 library file, and duplicates were removed and recorded in a separate folder. With the exception of the search in the databases for preprint archives and on the organization webpages, for which the screening process was conducted directly on the respective webpages, only articles selected at full text level were included in the EndNote X9 database.

\section{Article screening and study eligibility criteria Eligibility criteria}

The eligibility criteria were defined prior to screening to ensure that only articles relevant to the objective were included in the systematic map. All retrieved articles were assessed for relevance using the eligible criteria described in Table 2.

When there was doubt about the relevance of an article at all screening level, the article was included in the next step. Articles were excluded if an abstract was absent when imported from the scientific database to the EndNote library or if an abstract was not retrievable through online searches. Articles that were not accessible as full text online (through the SLU subscription or as open access) or available as printed versions through the SLU library were also excluded (see reason for exclusion in Additional file 4).

\section{Screening process}

Article screening was conducted at three levels: (1) title, (2) abstract and (3) full text. At each level, the articles were assessed following the eligibility criteria (detailed above). All articles excluded after the title and abstract levels were recorded in a separate list (Additional file 4).
Articles excluded at the full text level were recorded and assigned a reason for exclusion (Additional file 4). Eligible review articles, books, reports (with no relevant study design or experimental data not statistically evaluated), conference papers and registration of cultivar notes were recorded in a separate folder named "Book, reviews and reports" (Additional file 4), and these were not included in the systematic map. However, the reference lists of these articles were screened, and the research articles not identified in the database searches that fulfilled the eligibility criteria were added to the systematic map database. Peer-reviewed articles, reports with relevant study designs and statistically evaluated studies, and university theses were included in the systematic map.

The screening process for the articles obtained from the academic bibliographic databases was conducted by two reviewers independently at the three levels. At the end of the screening process, the results from both reviewers were compared, and any discrepancy at the full text level was discussed.

The consistency of eligibility decisions among the two reviewers was validated by a kappa test at the title, abstract and full text levels [17]. At the title and abstract levels, the kappa test showed substantial agreement (0.64 and 0.61, respectively), which is in accordance with the expected score defined in the systematic map protocol ( 0.6 or above). At the full text level, however, the initial kappa test showed moderate agreement $(k=0.54)$. After discussions about the disagreements and clarification of the eligibility criteria, the reviewers again analyzed the full text from the articles on which they first had disagreed and reevaluated them. Then, a second kappa score of 0.66 (substantial agreement) was obtained, which is in accordance with the expected score defined in the systematic map protocol. The few remaining disagreements were discussed and reevaluated jointly by the two reviewers until a common agreement was reached. The screening process for grey literature was conducted by just one reviewer, and the second reviewer checked and validated the articles selected at the full text level. Reviewers who were authors of eligible articles were not included in the decision connected to the evaluation of their articles.

\section{Study validity assessment}

Identification and assessment of the experimental design was performed when evaluating the relevance of a study and if it was eligible to be included in the map. This information was included in the coding of each study. No study validity assessment or critical appraisal was performed because the intention of this map is to provide a general overview of the available literature about disease control methods in oat production. 


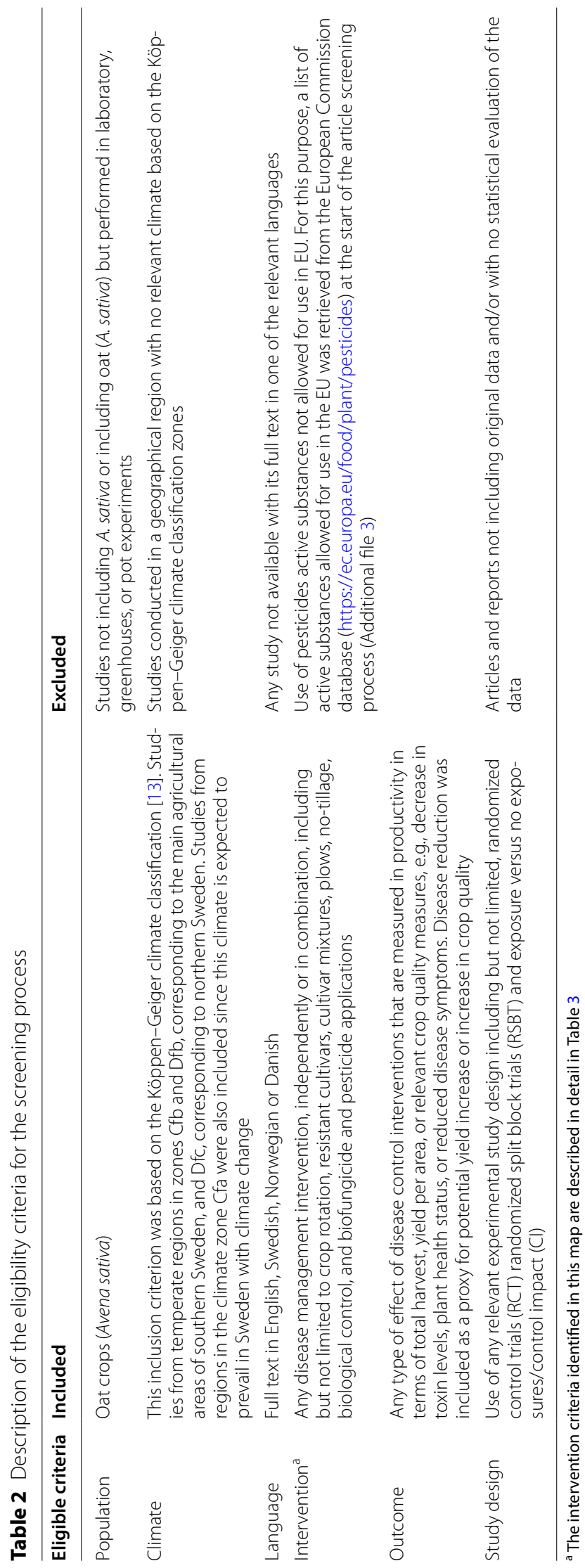




\section{Data coding strategy}

Standardized descriptive data from all articles meeting the eligibility criteria were exported from EndNote to an Excel spreadsheet, which formed the systematic map database. The following data variables of interest were extracted from the articles included in the systematic map: (i) bibliographic information; (ii) climatic zone(s); (iii) location(s) of study; (iv) disease name(s); (v) pathogen type(s); (vi) disease-causing organism(s); (vii) intervention and management method(s); (viii) diseased part(s) and plant stage(s); and (ix) the approach for measuring the outcome (for the detailed coding strategy, see Additional file 5). The coding of the intervention and management methods were carefully discussed and defined (Table 3).

Articles that included more than one disease were coded as one single study, and all diseases were noted, as occurred for other data variables. Articles that included oat and other crops were included in the systematic map, and in these cases, only information regarding oat was reported. The coding process was conducted by one reviewer and checked by a second reviewer, and any ambiguities were discussed and resolved.

Articles included in the folder "Book, reviews and reports" were categorized into five different groups: review articles in scientific journals, books or book chapters, conference papers, reports (with no relevant study design or not statistically evaluated), and registration of cultivars.

\section{Data mapping method}

All included articles and their metadata were recorded in a searchable Excel database available in Additional file 5.

A map of oat production in different countries and the number of articles from the different locations were produced using the map chart feature in Excel. Summary figures and tables of the interventions and management categories identified were produced to summarize and visualize the results. The number of publications per year, type of pathogen and disease and intervention are visualized in figures, while articles for each climatic zone and disease per country, as well as fungicide control measures, are presented in tables. As studies within individual articles sometimes included more than one disease type, intervention, and outcome category, individual articles were mapped as separate studies when adequate.

\section{Review findings \\ Search results}

The searches in five scientific databases and on Google Scholar resulted in 3439 records (Fig. 2). When duplicates were removed, 2712 records were included for the screening process, and 51 articles that met the eligibility criteria were included in the systematic map after

Table 3 Description of the disease control intervention and management strategies applied by the studies included in the systematic map

\begin{tabular}{|c|c|}
\hline Intervention/Management type & Description \\
\hline Cultivar resistance & Evaluation of different oat cultivars or varieties for resistance to diseases \\
\hline Pesticide application & $\begin{array}{l}\text { Use of any approved pesticide (for use in the EU) for disease control, including fungicides, growth regulators } \\
\text { and herbicides. Includes tests with different spraying rates and time points and comparisons between different } \\
\text { pesticides }\end{array}$ \\
\hline Soil preparation & $\begin{array}{l}\text { Use of agricultural practices for soil preparation (plowing, tillage, minimum tillage and no-tillage) as a disease } \\
\text { control management approach }\end{array}$ \\
\hline Soil amendments & $\begin{array}{l}\text { Use of soil fertilization for disease control (nitrogen and copper). Includes tests with different application rates } \\
\text { and times of application }\end{array}$ \\
\hline Cultivar mixture & Cultivation of a mixture of oat cultivars for disease control management \\
\hline Inoculum level & Addition of different levels of disease inoculum to plants to assess the effects on disease development \\
\hline Seed rate & Use of different seed rates to assess disease incidence in the field \\
\hline Sowing time & Implementation of sowing at different times to control disease development \\
\hline Crop rotation & Use of crop rotation as a disease control management strategy \\
\hline Cropping systems & $\begin{array}{l}\text { Comparison between different crop systems (conventional and organic systems) in terms of disease develop- } \\
\text { ment }\end{array}$ \\
\hline Integrated crop-livestock system & $\begin{array}{l}\text { Use of different integrated crop-livestock systems (agrosilvopastoral and agropastoral systems) to assess disease } \\
\text { development in oats }\end{array}$ \\
\hline Intercrop system & Use of multiple cropping practices to assess disease development in oats \\
\hline Lodging & Assess the effect of lodging on disease development and mycotoxin content in oat grains \\
\hline Seed thermal treatment & Assess the efficacy of seed thermal treatment for oat seed decontamination \\
\hline Time of harvest & Harvest on different dates to assess oat grain quality \\
\hline
\end{tabular}




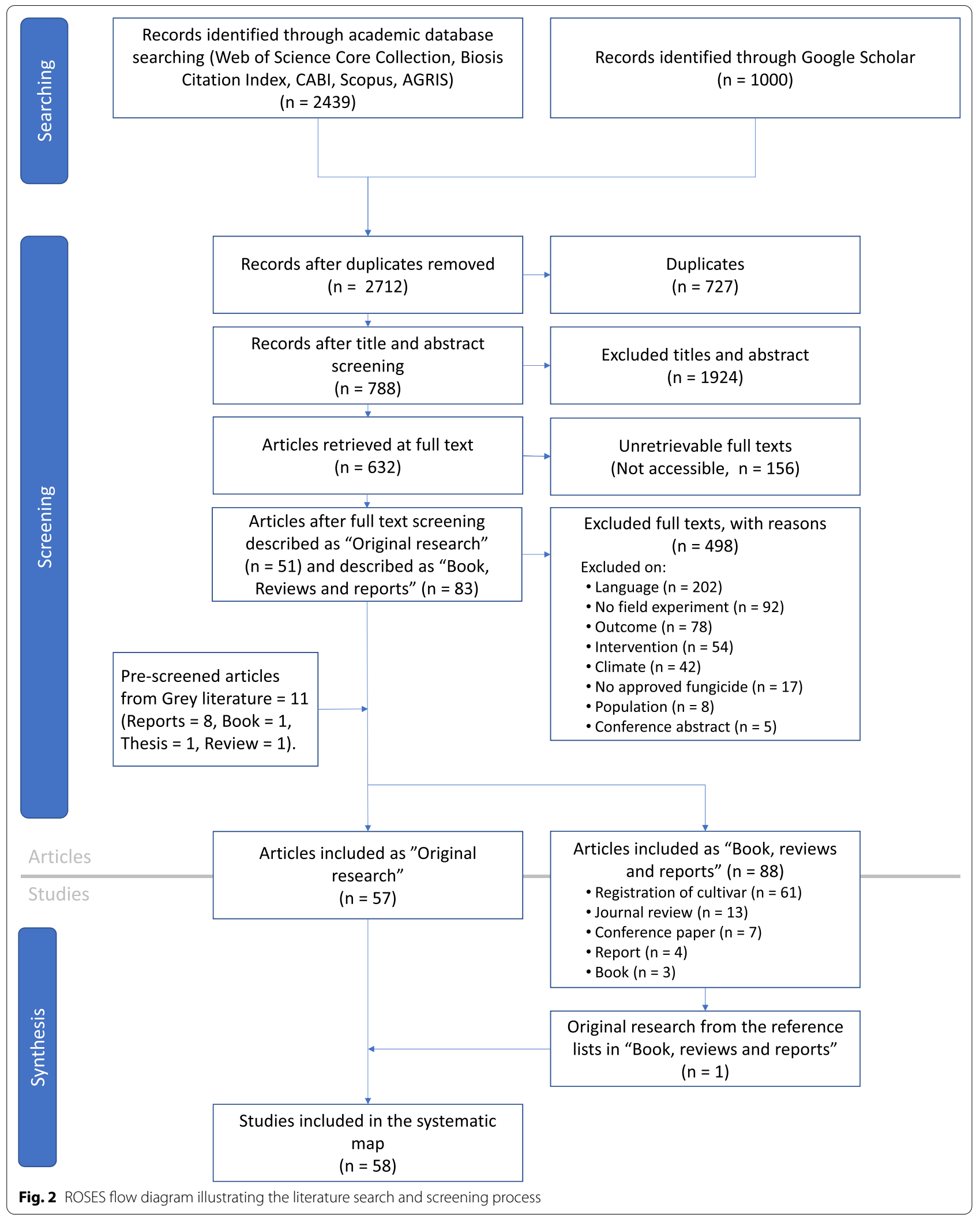


the screening at the title, abstract and full text levels. In addition, 83 eligible articles were included in the folder "Book, reviews and reports".

In total, 1924 records were removed at the title and abstract levels; 156 records were not accessible (online or at the SLU library), and 498 records were removed at the full text level. The reasons for exclusion at full text level were the following: language out of the review scope, experiments not conducted in the field, no relevant outcome, no relevant intervention, no relevant climate, use of nonapproved fungicides, and studies conducted with crops other than oat, and conference abstracts.

The grey literature prescreening conducted on organizational websites resulted in 11 eligible articles, six articles were included in the systematic map, and five articles were included in the folder "Book, reviews and reports". The reference list from the articles saved as "Book, reviews and reports" were screened, and one eligible article not found in the database search was identified and included in the systematic map.

In total, 58 eligible articles were included in the systematic map: 51 scientific journal articles, six project reports, and one M.Sc thesis. The articles were published by 40 different journals, organizations, or universities. All journal articles and four reports were written in English, two reports were written in Norwegian and the Master thesis was written in Swedish.

A total of 88 articles were included in the "Book, reviews and reports". The number of articles included in each of the five categories was: review articles in scientific journals $(n=13)$, books or book chapters $(n=3)$, conference contributions $(\mathrm{n}=7)$, reports $(\mathrm{n}=4)$, and registration of cultivars $(n=61)$.

\section{Geographical and temporal distribution of research}

The geographical distribution of the articles included in the systematic map and the number of articles per country are presented in Fig. 1. The majority of the studies were conducted in the Northern Hemisphere, where most of the world's oat production are located [4]. By country, Canada had the highest number of studies $(n=9)$, closely followed by Norway and Sweden, with eight studies each. In the Southern Hemisphere, the studies were conducted in Brazil $(n=3)$ and Australia $(n=2)$, currently the largest oat producers within their respective regions [4].

The majority of studies were conducted in regions with Dfb and Cfb climatic zones (Table 4), which correspond to the main climate of large parts of Canada and Europe.

It should be noted that for two articles, the studies were conducted in different countries and in different climatic zones, and in five of the articles, studies were conducted in different climatic zones within one country. Thus, the
Table 4 Number of studies found in the 58 articles included in the systematic map from different countries and grouped by climatic zones

\begin{tabular}{lcccc}
\hline Location of studies & Dfb & Cfb & Cfa & Dfc \\
\hline Sweden & 7 & 4 & & 1 \\
Norway & 7 & 3 & & \\
Canada & 9 & & & \\
UK & & 8 & & \\
Finland & 7 & & & \\
USA & 3 & & 3 & \\
Poland & 5 & & & \\
Russia & 4 & & & \\
Brazil & & 2 & 2 & \\
Australia & & & 2 & \\
Austria & 2 & & & \\
Bulgaria & 1 & 1 & & \\
Czech Republic & 2 & & & \\
Estonia & 2 & & \\
Germany & 1 & 1 & & \\
Switzerland & & 1 & \\
Ireland & & 1 & \\
Romania & & & \\
Belarus & & & \\
Hungary & 1 & & \\
Serbia & & & \\
Slovakia & & & \\
Total & 53 & & \\
\hline & 1 & & \\
\hline
\end{tabular}

total number of studies per location and climatic zone was different from the total number of articles included in the systematic map (Table 4).

Among the included articles, the earliest was published in 1980, followed by an oscillating temporal distribution of the studies over the following years, ranging from zero to five (Fig. 3).

\section{Pathogen type and diseases studied}

The disease-causing organisms were classified according to pathogen type. Among the articles included in the systematic map, fungi $(n=46)$ were the most common pathogen type (Fig. 4a). Viruses and nematodes were studied in ten and three articles, respectively. Bacteria were only reported in one article. It should be noted that two articles included experiments with two different pathogen types, and 12 articles included two or more diseases.

In total, 16 different diseases were reported by the articles included in the systematic map (Fig. 4b). More than half of the studies concentrated on just five diseases: Fusarium head blight (Fusarium spp.), crown rust (Puccinia coronata), Barley yellow dwarf virus (BYDV), leaf blotch (Pyrenophora avenae), and specked blotch 

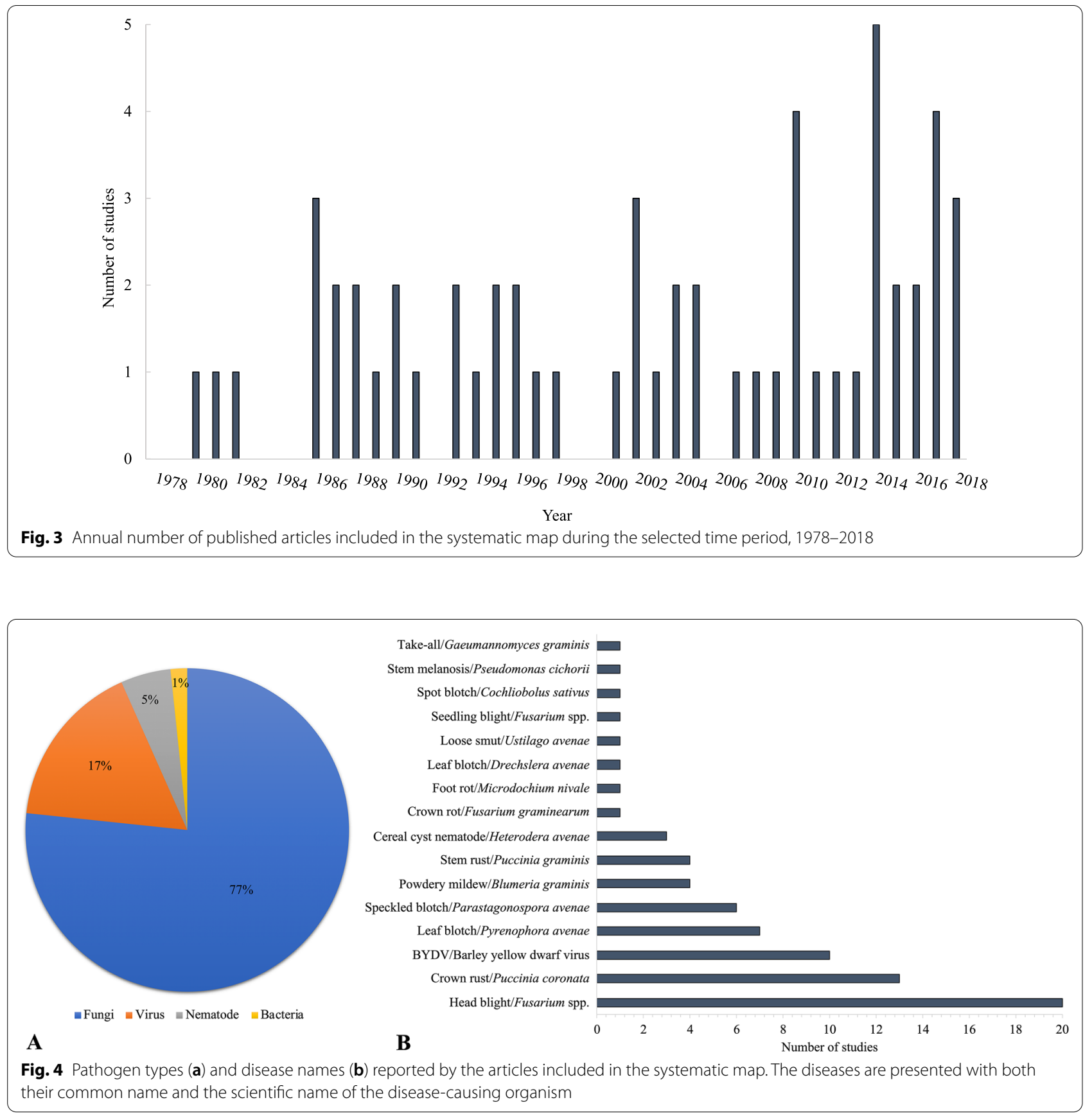

(Parastagonospora avenae). All of these are considered important oat diseases and cause serious economic losses in oat production worldwide. However, Fusarium head blight (FHB) is currently of the greatest concern due to mycotoxin production, which can lead to impairment of quality parameters [5]. FHB is caused by several Fusarium spp. that differ in prevalence depending on the region and climate [18]. These pathogens produce mycotoxins that can lead to chronic toxicity when consumed by animals and humans, even when mycotoxins are present at low levels [5]. For this reason, several countries have already created legislation to limit the level of mycotoxins in cereals for human consumption and animal feed. EU legislation has defined the allowable prevalence of the Fusarium mycotoxins deoxynivalenol (DON), zearalenone (ZEN), and fumonisins B1 and B2 [19] and provides recommendations for monitoring the presence of HT2 and T2 toxins in cereals [20]. 
The production of each specific mycotoxin depends on the Fusarium spp. infecting the plants and the weather conditions $[5,18]$. Among the FHB studies included in the systematic map, a total of six Fusarium spp. were analyzed (Fig. 5). In seven studies, there was no indication of the target species, and as a result, it was only noted as Fusarium spp. on the map. Fusarium culmorum and F. graminearum were the most studied species (three studies each), followed by $F$. langsethiae, $F$. avenaceum, $F$. crookwellense (syn. F. cerealis), and F. poae. FHB studies were conducted in Europe, Canada and Brazil (Table 5). In Canada and Brazil, F. graminearum, which is the most common species worldwide, was the only species studied [18]. In Europe, the most studied species were $F$. avenaceum, F. culmorum, and F. langsethiae, and the first two species (together with $F$. graminearum) are considered the most common species in Europe [18]. The best way, both economically and ecologically, to control FHB is an integrated approach based on the use of resistance genotypes [21]. However, there is little information about FHB resistance in oats because until recently, this disease was considered less important in oats than in wheat and corn. Currently, oat cultivars do not have good resistance to FHB, and the use of healthy seeds and good agronomic practices are recommended [22]. Increased effort and focus on breeding programs to develop oat cultivars resistant to FHB and mycotoxin production are needed [23].

Crown rust (P. coronata), the second most studied disease, is the most damaging fungal disease of oat worldwide and may cause substantial yield losses [9]. Among the articles included in the systematic map, crown rust was mostly studied in the USA and Canada (Table 5).
BYDV is the most important virus disease affecting oat and is transmitted by the bird cherry oat aphid Rhopalosiphum padi, and it was studied mainly in Finland and Sweden. Leaf blotch (P. avenae) is a common and devastating oat disease in humid and cool regions of Europe [24]. Leaf blotches have been studied mainly in Europe and in 13 different countries since two articles focused on varietal reactions to the disease in different European countries.

In the first 20 years within the searches for this map (1980-1999), studies that focused on the virus disease BYDV were the most common $(n=8)$. However, in the next 18 years (2000-2018), the highest number of studies focused on FHB $(n=18)$ and rust diseases $(n=13)$. The three field studies with cereal cyst nematodes (CCN) (Heterodera avenae) included in this map were all published in the 1980s (data not shown).

Research in crop protection is often a needs-driven process, where a problem or question is identified and research is conducted to solve that particular issue. When effective management practices against a disease (e.g., fungicides or resistant cultivars) are implemented, the need for research in that particular pathosystem becomes less urgent. One such example is BYDV, which was a serious problem in the 1980s, and the disease was successfully managed by the introduction of resistant cultivars and insecticides, limiting the aphid vector and spread of the disease. No publication was found between 2000 and 2018. The struggle to protect plants and improve disease management is continuous. Therefore, it is important to retain and update scientific knowledge about all diseases and their control and management strategies, particularly since climate change alters the risk for disease [25].

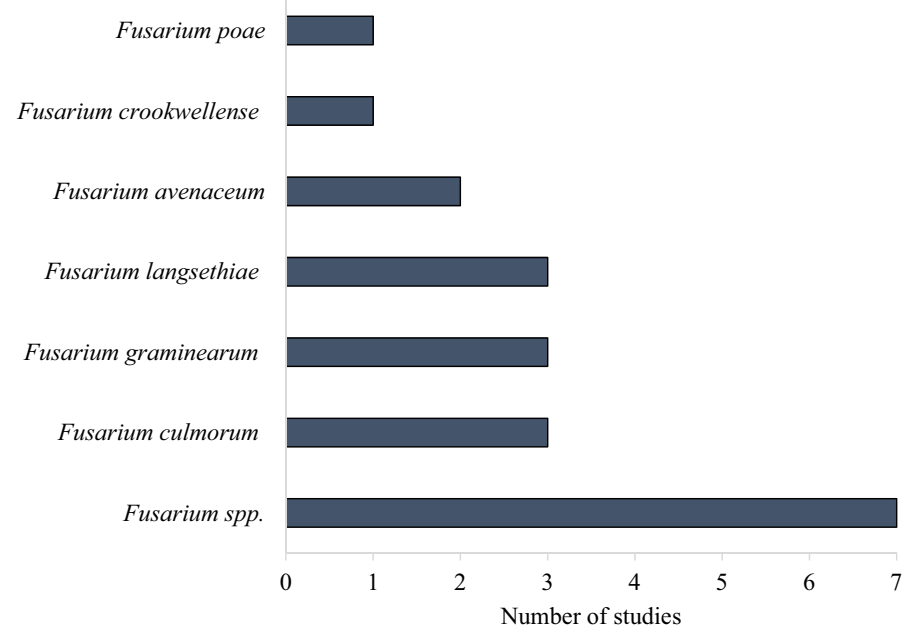

Fig. 5 Number of studies about the different species of Fusarium causing head blight reported in the articles included in the systematic map 


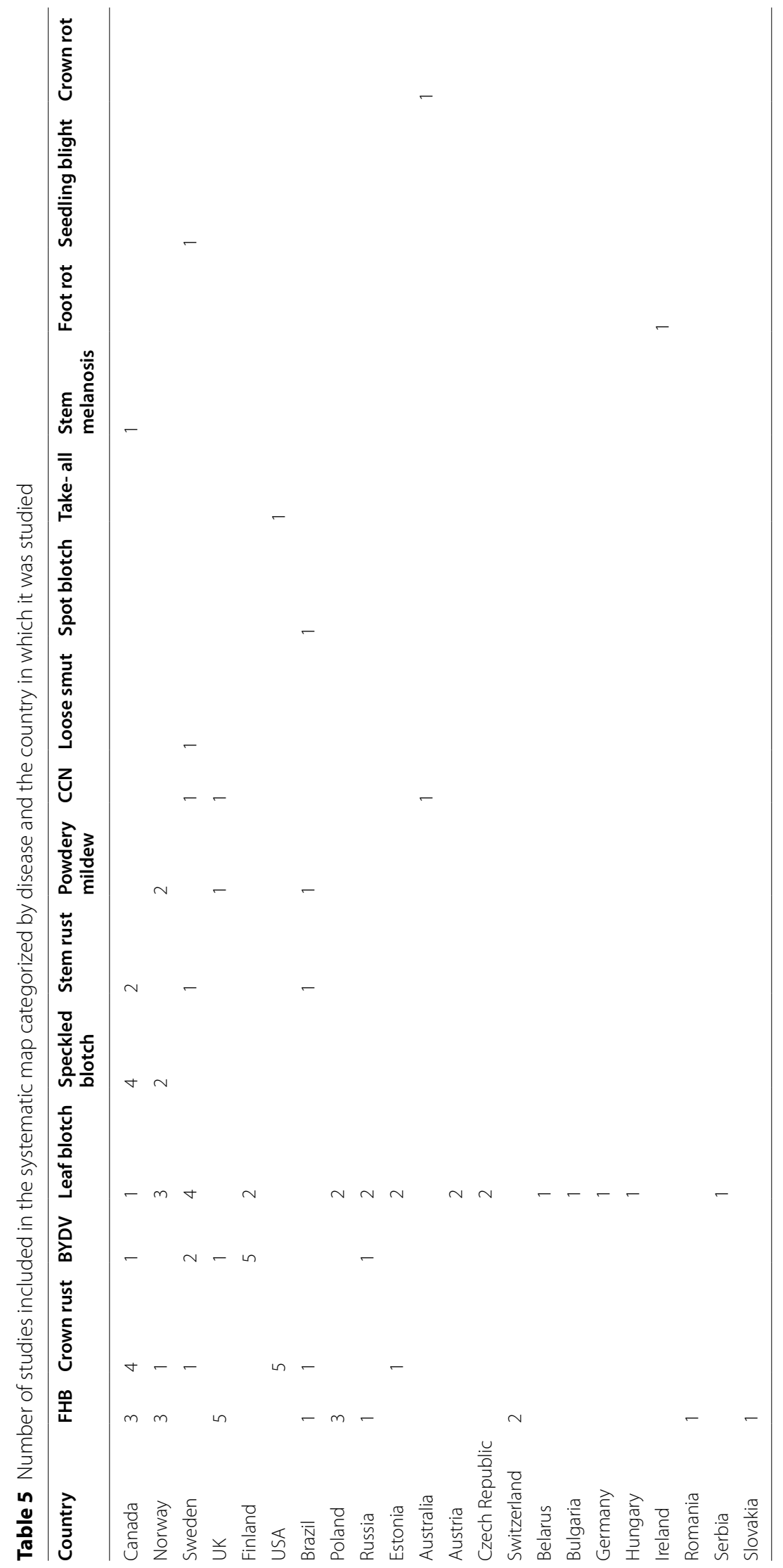




\section{Intervention type}

In total, 17 different intervention management types to control the diseases were included among the articles in this systematic map (Fig. 6). However, the majority $(\mathrm{n}=48)$ focused on cultivar resistance, and a few others $(n=15)$ focused on pesticide application. Other types of interventions were mainly related to agricultural management practices. It should be noted that 22 articles involved studies that conducted experiments with more than one intervention type (Fig. 6). Among these, 16 articles analyzed the intervention types in combination, and the remaining six articles only compared the results of different interventions. The combinations most studied were cultivar resistance and fungicide application $(n=6)$. Other intervention combinations were cultivar resistance and inoculum level $(\mathrm{n}=2)$; herbicide and soil preparation $(\mathrm{n}=2)$; cultivar resistance and soil amendments $(\mathrm{n}=2)$; cultivar resistance and sowing time $(n=1)$; cultivar resistance and seed rate $(n=1)$; cultivar resistance, fungicide and sowing time $(\mathrm{n}=1)$; and cultivar resistance, growth regulator and soil amendments $(\mathrm{n}=1)$. Studies evaluating cultivar resistance were identified for all diseases, with the exception of seedling blight (Table 6).

Fungicide was the most applied pesticide type and was mostly used for foliar diseases, especially for crown rust, leaf blotch, speckled blotch, and stem rust (Table 7).
In total, eight different active substances were used among the studies that used fungicide as an intervention. Pyraclostrobin was studied three times for crown rust and once for leaf blotch, speckled blotch, and stem rust control. Tebuconazole was studied twice for crown rust and once for leaf blotch, spot blotch, and stem rust control. Maneb was used once for BYDV, crown rust, and speckled blotch control. Imazalil was studied once for leaf blotch and loose smut control. Azoxystrobin and benzothiadiazole were studied once each for crown rust control. Fludioxonil was studied once for seedling blight control, and prothioconazole was studied once for crown rust control. The combination of different active substances (prothioconazole and pyraclostrobin) was studied in just one article with the aim of controlling crown rust. Growth regulators were applied in two studies of FHB control (trinexapac-ethyl and chlormequat) and in one study for speckled blotch control (chlormequat). Herbicide application was based on glyphosate and applied in one study to indirectly control FHB, in another study to control crown rust and speckled blotch, and in a third study to control leaf blotch and speckled blotch.

Fungicides are commonly used and effective in controlling fungal diseases, but continued use can lead to fungicide resistance and may have a negative environmental impact. In addition, disease control by fungicide

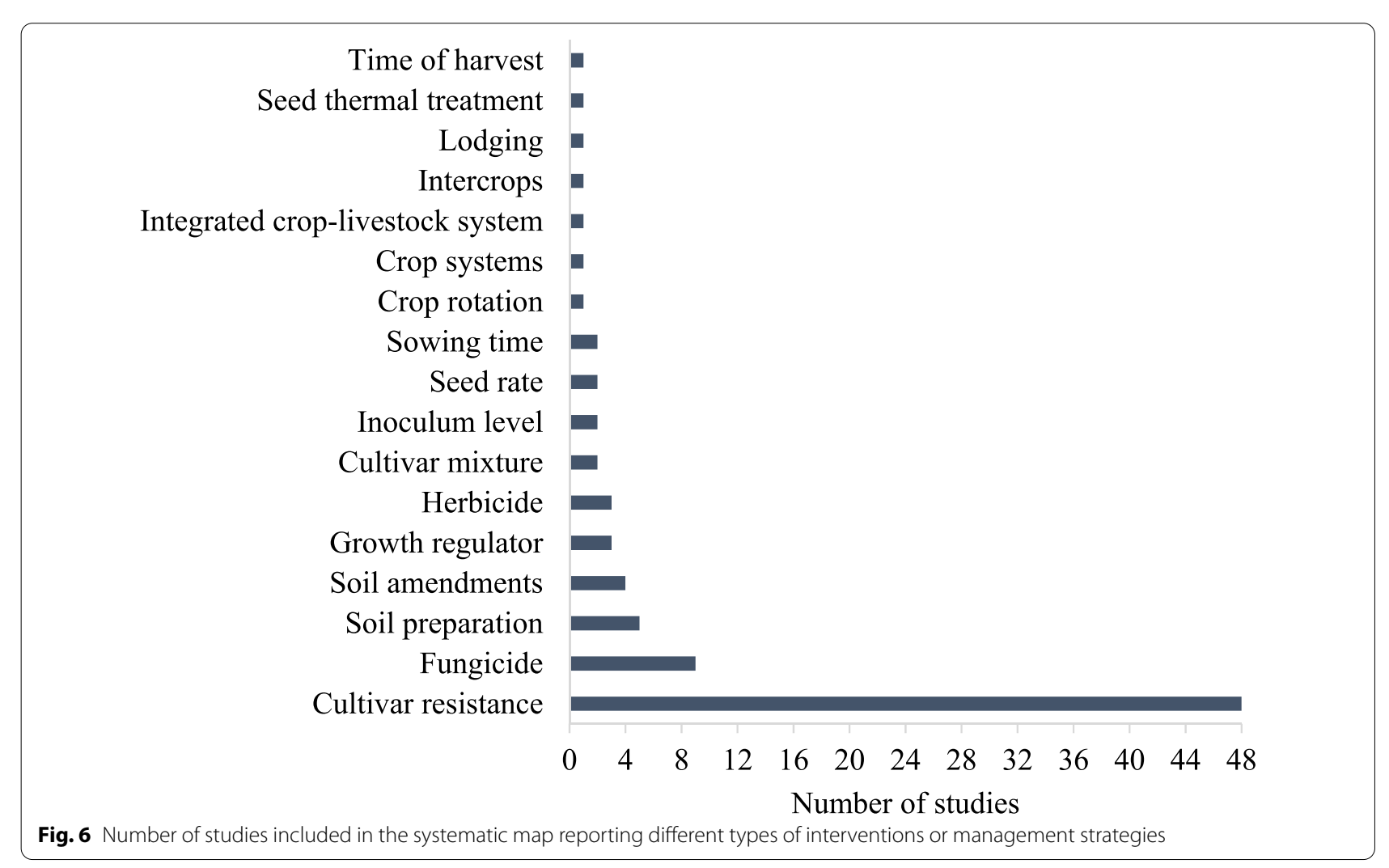




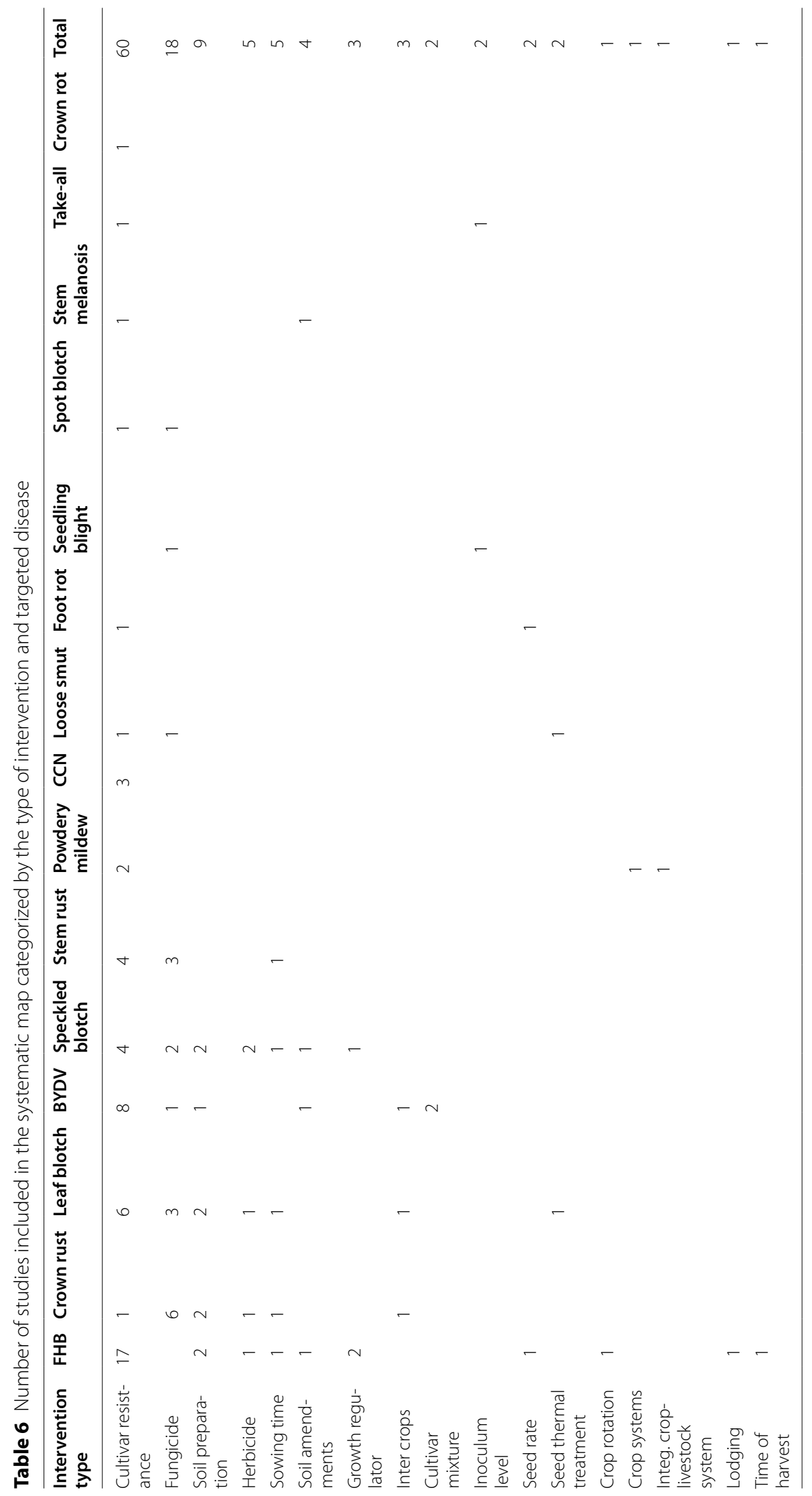


Table 7 Number of studies included in the systematic map that used any fungicide active substances and the targeted disease

\begin{tabular}{|c|c|c|c|c|c|c|c|c|c|}
\hline Fungicide active substance & Crown rust & Leaf blotch & $\begin{array}{l}\text { Speckled } \\
\text { blotch }\end{array}$ & Stem rust & BYDV & Loose smut & Seedling blight & Spot blotch & Total \\
\hline Pyraclostrobin & 3 & 1 & 1 & 1 & & & & & 6 \\
\hline Tebuconazole & 2 & 1 & & 1 & & & & 1 & 5 \\
\hline Maneb & 1 & & 1 & & 1 & & & & 3 \\
\hline Imazalil & & 1 & & & & 1 & & & 2 \\
\hline Azoxystrobin & 1 & & & & & & & & 1 \\
\hline Benzothiadiazole & 1 & & & & & & & & 1 \\
\hline Fludioxonil & & & & & & & 1 & & 1 \\
\hline Prothioconazole & 1 & & & & & & & & 1 \\
\hline
\end{tabular}

application is an added financial cost for farmers [10, 11]. For these reasons, studies should be conducted to develop efficient and environmentally friendly alternative approaches to disease control. Studies on fungicide should be conducted with currently or newly approved active substances and with a greater focus on integrated approaches, including good agricultural management practices that can improve the efficacy of the fungicide, decrease the fungicide rate applied, and ensure soil conservation. In this map, no field studies including biological control agents were identified. Future studies should also be directed toward the application of biological control agents in field experiments to investigate the efficacy of these agents and support nonchemical control strategies. The use of biological control agents for FHB control is of special interest since effective chemical control is difficult to achieve due to the need for precise fungicide application timing [18].

Among the agricultural intervention management practices, soil preparation was evaluated in two studies for FHB control (minimum-tillage and plowing) and in another two studies to control crown rust and speckled blotch and to control leaf blotch and speckled blotch (tillage and no-tillage). In a third study, soil preparation (plowing) was evaluated to control BYDV, crown rust, and leaf blotch (Table 6). Soil amendments were evaluated in four different studies to control BYDV, FHB, speckled blotch (nitrogen fertilization), and stem melanosis (copper fertilization). Cultivar mixtures were tested in two studies and only for BYVD control. The inoculum level was evaluated in two different studies to control take-all and seedling blight. The seed rate was included in two different studies to control FHB and foot rot (caused by Fusarium spp. and Microdochium nivale, respectively), and sowing time was tested in one study for FHB control and in another study for leaf blotch, speckled blotch, crown and stem rust control. Cropping systems (conventional or organic systems) and integrated crop-livestock systems (agropastoral and agrosilvopastoral systems) were evaluated in two different studies, and both were used for powdery mildew control. The use of intercrops was used in one study to control the development of BYDV, crown rust, and leaf blotch. A seed thermal treatment was evaluated in one study for leaf blotch and loose smut control. Crop rotation, lodging, and time of harvest were each evaluated once in different studies for the control of FHB.

\section{Limitations of the map}

The climatic selection criteria limited the geographical distribution of the included studies to regions where the climate corresponds to the current (Dfc, Dfb, and Cfb) and future predicted (Cfa) climate in Sweden, according to Köppen-Geiger climate classification zones [13]. Thus, many studies from countries with oat production (Fig. 1) located in areas other than those under the specified climate conditions were excluded from the systematic map.

In the development of the systematic map protocol, different search strings were tested to gather the most eligible studies for disease management in the six important field crops in Sweden. No set of papers for comprehensiveness test was compiled and thus this was not performed. After suggestion by reviewers, the search string was tested including the words "pesticid", "fungicid" and "herbicid". The alternative search string captured two additional eligible articles [26, 27], which could have been included in the systematic map. Therefore, future maps should include these words in the search string.

The selection criteria to include studies based on field trials resulted in a limited number of studies with nematodes since experiments with this organism group are normally conducted under controlled environmental conditions due to the difficulties of controlling their spread if applied in field trials, which results in a large environmental risk in terms of conducting field experiments. As an example, the $\mathrm{CCN}$ is a nematode species that causes serious economic damage [3] to oat 
production and only three studies were identified as field trials, and all were conducted in the 1980s.

Field experiments to evaluate fungicide efficiency and other agricultural cropping methods are often not officially published or published in reports in national language and are available for public use only on country-specific webpages. Thus, these sources may be difficult to identify and understand from outside the specific country or region where the study is published.

Breeding programs for host resistance are a key method for controlling plant diseases [28]. However, studies on breeding and prebreeding were not included since advancements in these articles are indirectly implemented in crop production, and new cultivars must also undergo registration before marketing. Registration of new cultivars $(\mathrm{n}=61)$ is thus included under "Book, reviews and reports" (Fig. 2). All new cultivars are not announced in a scientific journal and thus are not included here. For Sweden and other countries, information about new cultivars is included in plant variety gazettes by country.

\section{Conclusions}

We have provided a database with literature from which disease management strategies can be extracted and used in updating plant protection recommendations. To our knowledge, this is the first systematic map of crop protection. The method used in this study has great potential for developing sustainable crop protection strategies and could potentially be used for all types of crop management interventions. Here, we have focused on one crop and only diseases, while crop protection also includes the management of weed and insect pests. This systematic map collates and catalogs existing evidence for disease management of oat cultivated in temperate climates.

\section{Implications for research}

Although relevant field studies for oat disease management exist, the map highlights the low quantity of field research on this topic and the resulting knowledge gaps. For instance, no oat field studies with biological control agents were found. Host resistance was the intervention management most used in the studies included in the systematic map, and this approach is currently the most applied disease management strategy to control the main oat diseases worldwide [3, 9]. Oat breeding programs for disease resistance, however, still face many challenges. The newly resistant cultivars to rust diseases have short lifespans (an average of 5 years) due to the high evolutionary potential of rust pathogens $[9,10]$, which leads to a constant evolution of new virulent variants. As a result, continued breeding efforts to develop new cultivars with durable resistance to rust diseases are needed [29]. Breeding efforts should also be directed toward the development of oat cultivars with high resistance to FHB. In addition, further research should focus on a combined approach with different management strategies effective in controlling disease and, at the same time, causing the least possible environmental impact. A large body of results from field trials existed based on studies performed by private companies and/or published in local languages, resulting in limited access to the knowledge. It would be beneficial for all agricultural activities if this type of data would be published in an open access format. The use of scientifically relevant study designs and statistical analysis of field trials are essential.

Research on crop protection is often driven by a needsdriven research process, where stakeholders identify a problem or question that needs to be addressed with a systematic approach. Disease intervention methods are targeted to limit the amount of pathogen spread at the "weak" stage of the disease cycle to limit the negative impact on yield and quality of the yield. This systematic map has compiled an evidence base for use by researchers and extension organizations working in plant protection to identify new research topics that are relevant and need to be further studied.

\section{Implications for policy and management}

Applied research is often based on the availability of funding for a particular disease, and the number of studies is often linked to the economic importance of a disease. Therefore, this systematic map can be useful for decision-makers and funding organizations to better prioritize research topics on plant protection that need further research, allowing a more impactful allocation of available resources.

The map provides an overview of the available disease protection management options for oat production in Sweden and will be a useful tool for field-based advisors to provide scientific-based plant protection strategies for farmers. In addition, collaboration among farmers, advisors, and researchers is crucial for knowledge transfer and the development of relevant research questions and scientific insights to be applied in practice.

\section{Supplementary Information}

The online version contains supplementary material available at https://doi. org/10.1186/s13750-021-00239-7.

Additional file 1. ROSES for Systematic Map Reports Version 1.0.

Additional file 2. Descriptive information about the results from searches performed in scientific databases and grey literature, including a list of relevant organizational webpages.

Additional file 3. List of pesticides active substances approved for use in the EU. 
Additional file 4. List of articles removed at the title/abstract and full text levels, and list of articles included in the folder "Book, reviews and reports".

Additional file $\mathbf{5}$. Oat systematic map database.

\section{Acknowledgements}

Björn Andersson and Anders Lindgren for valuable comments on the manuscript.

\section{Authors' contributions}

$\mathrm{AB}$ and $\AA \mathrm{O} O$ planned the project. JT conducted the searches. $\AA \mathrm{O}$ and EV performed the screening of the material. AB, $\AA \mathrm{O}, \mathrm{ACW}$ and EV contributed to the critical assessment, and EV wrote the draft manuscript, and all authors contributed to the final version. All authors read and approved the final manuscript.

\section{Funding}

Open access funding provided by Swedish University of Agricultural Sciences. This research was supported with funding from SLU Future Foods (Sveriges Lantbruksuniversitet) and Swedish Board of Agriculture open call as well as FORMAS (Svenska Forskningsrådet Formas) special call "National research program for food-First call: synthesis within the food area", Grant number 20017-02028.

\section{Availability of data and materials}

All data generated or analyzed during this study are included in this published article and in its supplementary files.

\section{Declarations}

\section{Ethics approval and consent to participate}

No ethical approval was necessary for this study.

\section{Consent for publication}

Not applicable.

\section{Competing interests}

The authors declare that they have no competing interests.

\section{Author details}

${ }^{1}$ Department of Forest Mycology and Plant Pathology, Swedish University of Agricultural Sciences, Box 7026, 75007 Uppsala, Sweden. ${ }^{2}$ Rural Economy and Agricultural Society HS Konsult AB, Gamla vägen 5G, 70227 Örebro, Sweden.

Received: 31 May 2021 Accepted: 22 September 2021

Published online: 09 October 2021

\section{References}

1. Ma B-L, Zheng Z, Ren C. Chapter 6-Oat. In: Sadras VO, Calderini DF, editors. Crop physiology case histories for major crops. Cambridge: Academic Press; 2021. p. 222-48.

2. Murphy JP, Hoffman LA. The origin, history, and production of oat. In: Marshall HG, Sorrells ME, editors. Oat science and technology. Madison: American Society of Agronomy; 1992. p. 1-28.

3. Zwer PK. Oats. In: Wrigley C, editor. Encyclopedia of grain science. Oxford: Elsevier; 2004. p. 365-75.

4. FAO. Food and Agriculture Organization of the United Nations: FAOSTAT statistical database. 2021. http://www.fao.org/faostat/en/\#home. Accessed 21 Jan 2021

5. Stewart D, McDougall G. Oat agriculture, cultivation and breeding targets: implications for human nutrition and health. Br J Nutr. 2014;112(Suppl 2):50-7.

6. Hoffman LA. World production and use of oats. In: Welch RW, editor. The oat crop: production and utilization. Dordrecht: Springer; 1995. p. 34-61.

7. Marshall A, Cowan S, Edwards S, Griffiths I, Howarth C, Langdon T, et al. Crops that feed the world 9. Oats - a cereal crop for human and livestock feed with industrial applications. Food Secur. 2013;5(1):13-33.
8. Rasane P, Jha A, Sabikhi L, Kumar A, Unnikrishnan VS. Nutritional advantages of oats and opportunities for its processing as value added foodsa review. J Food Sci Technol. 2015;52(2):662-75.

9. Bowen KL, Hagan AK, Pegues M, Jones J. Yield losses due to crown rust in winter oats in Alabama. Plant Health Prog. 2016;17(2):95-100.

10. Cabral AL, Gnanesh BN, Fetch JM, McCartney C, Fetch T, Park RF, et al. Oat fungal diseases and the application of molecular marker technology for their control. In: Goyal A, Manoharachary C, editors., et al., Future challenges in crop protection against fungal pathogens. New York: Springer; 2014. p. 343-58.

11. McCallum BD, Fetch T, Chong J. Cereal rust control in Canada. Aust J Agric Res. 2007;58(6):639-47.

12. Berlin A, Källström HN, Lindgren A, Olson Å. Scientific evidence for sustainable plant disease protection strategies for the main arable crops in Sweden. A systematic map protocol. Environ Evid. 2018;7(1):31.

13. Kottek M, Grieser J, Beck C, Rudolf B, Rubel F. World Map of the KöppenGeiger climate classification updated. Meteorol Z. 2006;15(3):259-63.

14. Collaboration for Environmental Evidence. In: Pullin A, Frampton G, Livoreil B, Petrokofsky G, editors. Guidelines and standards for evidence synthesis in environmental management, Version 50. 2018.

15. Haddaway NR, Macura B, Whaley P, Pullin AS. ROSES for systematic map reports version 1.0. 2017. Figshare. https://doi.org/10.6084/m9.figshare. 5897299.v3.

16. Adams D. Publish or perish on macOS. 2016. https://harzing.com/resou rces/publish-or-perish/os-x. Accessed 15 July 2020.

17. Viera AJ, Garrett JM. Understanding interobserver agreement: the kappa statistic. Fam Med. 2005;37(5):360-3.

18. Karlsson I, Persson P, Friberg H. Fusarium head blight from a microbiome perspective. Front Microbiol. 2021;12(371):628373.

19. Commission regulation number $1881 / 2006$ setting maximum levels for certain contaminants in foodstuffs. Brussels: The Commission of the European Communities. 2006. https://ec.europa.eu/food/safety/chemi cal_safety/contaminants/catalogue/fusarium_en. Accessed 20 Mar 2021.

20. Commission recommendation number 2013/165/EU on the presence of T-2 and HT-2 toxin in cereals and cereal products. Brussels: The Commission of the European Communities. 2013. https://ec.europa.eu/food/ safety/chemical_safety/contaminants/catalogue/fusarium_en. Accessed 20 Mar 2021.

21. Šliková S, Šrobárová A, Šudyová V, Polišenská I, Gregová E, Mihálik D. Response of oat cultivars to Fusarium infection with a view to their suitability for food use. Biologia. 2010;65(4):609-14.

22. Hysing S-C, Wiik L. Fusarium seedling blight of wheat and oats: effects of infection level and fungicide seed treatments on agronomic characters. Acta Agric Scand B Soil Plant Sci. 2014;64(6):537-46.

23. Yan W, Pageau D, Martin R, Cummiskey A, Blackwell B. Is deoxynivalenol contamination a serious problem for oat in Eastern Canada? Crop Sci. 2017;57(1):88-98.

24. Šebesta J, Zwatz B, Roderick HW, Corazza L, Starzyk MH, Reitan L, et al. Incidence of Pyrenophora avenae Ito et Kurib. In Europe between 19941998, and the varietal reaction of oats to it. Plant Prot Sci. 2001;37:91-5.

25. Garrett KA, Nita M, De Wolf ED, Esker PD, Gomez-Montano L, Sparks AH. Chapter 24-Plant pathogens as indicators of climate change. In: Letcher TM, editor. Climate change. 3rd ed. Amsterdam: Elsevier; 2021. p. 499-513.

26. Bernhoft A, Torp M, Clasen PE, Loes AK, Kristoffersen AB. Influence of agronomic and climatic factors on Fusarium infestation and mycotoxin contamination of cereals in Norway. Food Addit Contam Part a Chem Anal Control Expos Risk Assess. 2012;29(7):1129-40.

27. Mourtzinis S, Conley SP, Gaska JM. Agronomic management and fungicide effects on oat yield and quality. Crop Sci. 2015;55(3):1290-4.

28. Van de Wouw AP, Idnurm A. Biotechnological potential of engineering pathogen effector proteins for use in plant disease management. Biotechnol Adv. 2019;37(6):107387.

29. May WE, Ames N, Irvine RB, Kutcher HR, Lafond GP, Shirtliffe SJ. Are fungicide applications to control crown rust of oat beneficial? Can J Plant Sci. 2014;94(5):911-22.

\section{Publisher's Note}

Springer Nature remains neutral with regard to jurisdictional claims in published maps and institutional affiliations. 